\title{
COACHING INTERVENTIONS FOR POSTGRADUATE SUPERVISION COURSES: PROMOTING EQUITY AND UNDERSTANDING IN THE SUPERVISOR-STUDENT RELATIONSHIP
}

\author{
M. Keane \\ Centre for Learning, Teaching and Development \\ University of the Witwatersrand \\ Johannesburg, South Africa \\ e-mail: moyra.keane@wits.ac.za
}

\section{ABSTRACT}

There is considerable research which supports the view that the student's ability to complete a doctorate is often fraught with factors relating to the complexity of their professional, personal and community contexts. In increasingly pressured settings, the quality of postgraduate supervision is critical, as is supervisory training.

In this article, I argue that some of the contextual difficulties experienced by supervisors and students could be addressed through the use of coaching principles and processes which help to open up conversations around selecting, reshaping and expanding ideas. These are the three aspects of Sternberg's Triarchical Theory which includes contextual intelligence (Sternberg 1997). I draw on data from postgraduate and supervisor courses I have facilitated at a number of universities in South Africa. I am not attempting a thorough analysis of the data; instead, I am using it as a rationale to show how contextual influences on professional academic development may be more consciously addressed. I first outline some of the pedagogical principles of three coaching models and then give three examples of coaching tools I have used in courses for supervisors.

Keywords: professional academic development, postgraduate supervision, coaching, higher education context

\section{INTRODUCTION}

'Why does she keep asking me what I think?' (PhD student 2015)

This quote was the confessed thought of one of my now-graduated $\mathrm{PhD}$ students. We laughed when she told me five years later that this is what she had kept wondering as I was supposed to be the 'expert'. The entrenched power divide had meant it took years for me to discover her thoughts about my supervision practice. Deep and frank conversations are difficult to initiate especially in crossing cultural or national divides (Geber and Keane 2013). I had missed a point made by Blackmore, Chalmers, Huxley and Thackwray $(2010,8)$ that development should be 
'based on context'.

Postgraduate supervision is a complex process that involves political pressures, adherence to policy, evolving pedagogical structures and prolonged supervisor-student relationships (Hadingham 2010). Coaching pedagogy is based on deepening self-awareness, improving cultural intelligence and communication (Middleton 2015), exploring values, setting goals and being accountable. I propose that the dual 'learning and action' based thrusts of coaching could be of use to supervisors and students, especially in the inequitable context of South Africa. Key principles of coaching that are relevant in this context are the levelling of power-relations, developing agency, fostering relationships and ensuring accountability. Especially in resourceconstrained contexts, coaching need not be a separate intervention for postgraduate students; it could be provided by supervisors who have had some training in coaching principles.

The arguments I make draw on literature on postgraduate supervision as well as data from student and supervisor workshops I have facilitated and co-facilitated nationally. This data includes: student issues related to their supervision experience; student expectations; some perceptions of the qualities of a good supervisor; 'Advice to supervisors from doctoral students'; and - 'What you would have liked to tell your student / supervisor but did not.' This workshop-based data reveals gaps in the expectations between students and supervisors and some of the communication and relational issues between them that they typically do not adequately address.

By introducing coaching tools that open up spaces for culturally sensitive dialogue, there is a possibility of acknowledging different perspectives and values, and for exploring new, relevant processes that contribute to the surfacing of issues of privilege, ethnicity and race. The three coaching tools include: 1) an informal learner-centred agreement on how the relationship can be set up to best serve both student and supervisor; 2) a self-assessment tool to provide a 'snapshot' of areas of development/concern/achievement; 3) a 'values' worksheet that provides a way of better understanding one’s working style and motivation.

These tools are intended to be used in conjunction with other processes of questioning, listening and setting goals. I provide examples of how the coaching interventions were used and argue that supervision courses could draw on these to provide holistic support, deepen selfreflection, encourage more equitable communication between supervisor and student, as well as promote accountability. All these features of development also provide practical ways to advance a transformation agenda in higher education.

My rationale for designing coaching interventions in Supervisor workshops is based on the premise that supervision is a complex process that rests heavily on relationship and 
communication, in addition to pedagogy. I propose that the dual learning and action-based thrusts of coaching could be of use to supervisors and students especially in the inequitable context of South Africa, as a key principle of coaching is a levelling of power-relations.

While there may be some specific coaching and mentoring programmes available for doctoral students, I am not here addressing such programmes as would be implemented at a structural level. I am proposing coaching tools that supervisors may themselves use with their students.

\section{A NEED FOR OPENING UP FRANK AND EQUITABLE CONVERSATIONS}

In their work Supervision of Supervisors, Emilsson and Johnsson (2007) present a list of supervisors' perceived difficulties in becoming more effective. Three of the seven problems listed were relational in nature. One supervisor phrased the problem as a 'Need for greater frankness' $(2007,174)$. I highlight this aspect as I later argue that coaching approaches help in providing structure that may facilitate greater equity and frank dialogue. In various studies into supervision, aspects of the supervisor-student relationship emerge, as well as the notion that pedagogy itself '... is a relational concept since it refers to what happens between the authorized pedagogues and students’ (Kamler and Thomson 2006, 18).

Hadingham (2010) acknowledges that the $\mathrm{PhD}$ journey is one that can be emotionally fraught, yet her contention is that the supervisor is not central to the student's success. This is partly because support roles and deep dialogues that promote epistemological access can be provided by other mentors and colleagues. This argument does not contradict my assertion that relationships and empowering conversations are central to PhD pedagogy. Fataar (2013), in outlining a pedagogy of supervision, proposes 'active relational engagement' which includes understanding the personal dynamics in the student's life. Wisker and Robinson (2012) propose a positive, sensitive model for student-supervisor relationships as they explore student wellbeing and resilience, while they draw our attention to some of the reasons for the difficulties doctoral 'orphans' experience, and suggest ways of dealing with these. In my view, the actual processes offered by coaching interventions may provide useful additions to this approach.

The definition of coaching that I use and expand on in the following sections is one of assisting a student or 'coachee' to explore their own motivation, set goals aligned with personal values, reflect on the learning steps to achieve the goals while also challenging a student and keeping her accountable (Kimsey-House, Kimsey-House, Sandahl, and Whitworth 2011). Coaching is not therapy where there is the assumption that the client needs healing. Unlike therapy, coaching is forward-focused and based on the assumption that the student is capable 
and resourceful. From this perspective, a coaching pedagogy is learner-centred: the student is encouraged to take control and demonstrate initiative. Students are not necessarily automatically aware of the need to develop their own agency - as the quote from a mature $\mathrm{PhD}$ student below illustrates. This is an extract from a coaching conversation. In this case, the coach is not the supervisor but a designated $\mathrm{PhD}$ coach:

Student: In supervision I want to bring in my own voice. I also need to make my weaknesses clear to me and to be able to say this is the support I need.

But how can I let supervisors know my weaknesses from my point of view - not theirs?

Coach: What is your role?

Student: (pause...) I never thought I had a role - I only thought of myself as a student under supervision $-\ldots$ a supervisor meant someone with 'superior vision'. ${ }^{1}$

This view of supervision aligns with Sue Clegg's description of supervisors who are often assumed to be 'looking-over' the student (Clegg 2014). This seems to be the assumption of the student here. By contrast, coaching takes the perspective of Hadingham $(2010,68)$ in her thesis on $\mathrm{PhD}$ candidates in South Africa. She argues that $\mathrm{PhD}$ candidates are: '... capable of making decisions about their research without the need for direction. By the same logic, should they require such direction, they have the agency to ask for it'.

The principles of agency and conscious, power-sharing relationships are central to coaching and these principles may contribute to providing some amelioration to the relational power gradient that works against the student's sense of agency in the supervisory relationship. Grant (2001) identifies power issues as complicating postgraduate pedagogy. Cited in the conclusion of a large study of 17000 doctoral students, two quotes illustrate the need students felt for greater sharing and sense of agency: 'I should have been more assertive in getting a response out of my supervisor - I always worried about he’s really busy ...’; ‘... I didn’t really appreciate how hard it would be and how much support would help ...' (HEFC 2012, 71). There are several emotional, motivational and social factors that delay or derail a student (Else 2014). This is dramatically expressed by Castle $(2013,1)$ in the statement 'I had no time to bleed' the title of her paper on $\mathrm{PhD}$ students. Many of these factors lead to 'academic procrastination' and, arguably, contribute to frustration, a lack of tolerance and low self-esteem (Ahern and Manathunga 2004). Supervisors on the Wellcome Trust PhD training programme in the UK acknowledge that they need to provide students with inspiration when they are struggling (Frame and Allen 2002). It is interesting that countries with a longer history of producing $\mathrm{PhD}$ graduates are experiencing many of the same issues that we experience in South Africa. Perhaps 
this is not surprising as we have, to a large extent, adopted the British model of one-on-one supervision (Dietz, Jansen and Wadee 2006), which possibly exacerbates students' feelings of isolation and if they have emotional, motivational or simply 'life' challenges, they may not have a peer cohort to lean on.

Considering this probably need for support doctoral students could be assisted in developing resilience, self-confidence, self-efficacy and learning more about how they can ‘chart their own path’ (Wadee, Keane, Dietz and Hay 2010) through coaching conversations, processes and tools. I argue that although the more transformative aspects of supervision are usually considered appropriate for coaching, coaching strategies span the five approaches identified by Lee (2006): functional; enculturation; critical thinking; emancipation; and relational. An example would be that coaching ensures that the student is organised and accountable (functional); conversation would identify networks, support structures and disciplinary values (enculturation); the student reflects and comes up with her own solutions (critical thinking); grows as a human being through a holistic approach (emancipation). Of course, this is based on a frank and positive relationship which can provide modelling of how this can continue with other colleagues (relational). While this is a loose correlation with Lee, I wish to signpost how the processes I go on to describe build on earlier approaches. I relate some of the comments of supervisors and students to these supervisory approaches identified by Lee.

\section{SUPERVISOR WORKSHOPS}

The supervisor workshops that I have designed and run with colleagues (see acknowledgement of Wadee and Castle) have taken various forms. We have run a series of two, two-day supervisor workshops with supervisors whose students are on the SANPAD-SANTRUST programme at various universities in South Africa and Ethiopia. In these workshops, we introduce coaching principles and tools. The supervisors' PhD students complete a year-long $\mathrm{PhD}$ proposal programme and then participate in part of the second supervisor's workshop. Here the supervisors coach their students using the principles and processes they have learnt. Part of the data presented here is drawn from feedback from students and supervisors on the programme.

Other workshops are for university staff at our institution. These are either one- or twoday supervisor workshops for academics with diverse experience and from different faculties. The coaching component of the workshops is similar to that of the SANPAD programme. Finally, we have also run workshops for postgraduate students at a university in Johannesburg 
on 'How to manage your supervisor'. These workshops include coaching tools and aim (among other outcomes) to develop student agency and self-efficacy. All these workshops align with the recommendation from Pearson and Brew (2002) that an important outcome of a supervisory training programme is that the supervisor's practice is adaptable and addresses broader issues beyond the research. The following questions arise: What are the broader issues? What is not being said? How can we open up spaces for frank and constructive conversations? Students and supervisors in the workshops have offered some insights.

\section{PERSPECTIVES FROM SUPERVISORS AND STUDENTS}

In workshop activities, students wrote down 'Advice they wish they could give their supervisors'. I provided some examples that could be resolved or facilitated by coaching interventions. This included comments related to the personal, affective, cognitive and academic identity. Students ‘advise’ supervisors:

Build, mentor and help your students become confident.

Encourage us often.

Understand my family and other social commitments.

Understand that I am still new at this; explain what you think is obvious - it is necessary for us.

Do not cut me off before giving me a proper chance.

Do not hold my hand but push me in the right direction.

Teach us the game of academia.

Be on track with your student's learning curve.

Be frank with me but supportive.

In the same workshops, supervisors' comments were mostly about time-management, responsibility and hard work. Supervisors said:

Submit on time.

Observe deadlines / work consistently.

A few supervisors' statements referred to cognitive aspects and some included personal comments:

I would like to hear your doctoral voice.

Read voraciously.

Do not presume any findings.

Ask for help.

Do not take criticism personally. 
As these comments are simply illustrative of frank perceptions from students and their supervisors about the supervisory process, I present them here as a suggestion that greater connection in intentions, goals, and expectations would be useful. This is further highlighted in workshops with students on 'How to manage your supervisor'. Students felt strongly that a great deal of the responsibility lay with their supervisor:

The supervisor should support the student regardless of his/her opinion of the students' capability. The supervisor should ensure that the thesis is finished in minimum time.

The supervisor should check constantly that the student is on track and working consistently.

The supervisor should ensure that the student has access to all facilities.

It was from reflecting on such conversations and feedback that the facilitators introduced the intervention of a 'designed alliance' which I will describe in the next section on coaching. I note here that not all 'unspoken conversation' hinged on the negative. If students had seen what some supervisors had written they might have been greatly encouraged. Examples include:

Don't be scared: I trust you with my time, because I believe in you; believe in yourself at least as much.

Stay I touch. I like that. I love PhD supervision. Use me, please!

From the students were statements such as:

Thank you for letting me do my own thing, trusting my decision-making.

Thank you, you have always believed in me and guided me.

Thanks - and you did not stretch me enough.

\section{HOW MAY SUPERVISORS FACILITATE ACCESS AND SUCCESS?}

The student comments appear to identify a range of supervisory approaches (see Lee's categories described above) that they find supportive. Three main approaches are seen in the following examples):

- Relational: Build ...; encourage; don’t cut me off; understand my family commitments ...

- Enculturation: Understand that I am still new at this ...; Teach us the game of academia ...

- Emancipatory: Don’t hold my hand ...; help your students become confident ...; be frank ...; Do not cut me off and Thank you for letting me do my own thing, trusting my decisionmaking. 
The functional aspects of the postgraduate work students seem to see as resting more with the supervisor:

The supervisor should ensure that the thesis is finished in minimum time.

The supervisor should check constantly that the student is on track and working consistently.

At the same time, supervisors often have a strongly functional approach and expect students to self-organise, manage time and think critically. Whether this implies an assumed universityreadiness more typical of second- or third-generation university students would require further investigation. What is clear is that supervisors and students, for the most part, express different priorities. It would be helpful for supervisors to be more aware of the gaps between their expected learning engagements and outcomes for the student and the student's support needs and priorities. Supervisors also need to consider how to deal with contentious expectations such as: 'the supervisor should support the student regardless of his/her opinion of the student's capability' and 'the supervisor should ensure that the thesis is finished in minimum time'.

I argue here that coaching offers strategies for voicing these perspectives and opening up possibilities to address them.

\section{THE ROLE OF COACHING STRATEGIES IN SUPERVISION}

\section{Coaching}

Coaching has been widely reported as an effective process to increase self-efficacy - the confidence one has in having the capability to carry out a significant task, to accomplish a goal (Rhodes 2013). While coaching is often considered as a useful tool for individual and organisational development (Grant, Passmore, Cavanagh and Parker 2010) and has been used successfully as an adjunct support for postgraduate students (Geber 2010; Geber and Visser 2012), what is proposed here is using selected coaching tools in supervisor training, for supervisors to use with their students.

Coaching's multiple theoretical roots come from philosophy, sociology, anthropology, sport, communication and natural sciences (Theeboom, Beersma, and van Vianen 2014). In relation to supervisor practices, Person and $\operatorname{Kayrooz}(2007,104)$ provide a number of constructs of coaching, including 'Providing advice on the logistics for producing a thesis document; provides specialist/expert expertise ...'. This conception of coaching (as directing and advising) is taken up by Bitzer and Albertyn (2011) in their framework for postgraduate supervision 
planning. While I acknowledge the alignment of this approach with the conventional supervisory role, the coaching models I am proposing in this article make a distinction between the 'sports coach' model and as mentoring that may involve telling the protégé what to do advice that comes from an expert and directs. Lee $(2007,686)$ describes a mentor as 'a nonjudgemental advisor' - which can be very useful for emerging researchers. In coaching, however, the aim of discussion is eliciting the student's perspective rather than giving advice. The definitions of coaching that I use are more aligned to deep approaches to learning, selfdirected learning and experiential learning. Coaching encourages inquiry, self-discovery and greater awareness of one's own ways of working and patterns of thinking. A coach will facilitate reflection and put in place negotiated targets based on the goals that are chosen by the student (Kimsey-House et al. 2011).

Choice and inquiry are essential features of a liberating and humanising education (Freire 1970). In Shor and Freire $(1987,13)$ this argument is continued: 'Besides being an act of knowing education is a political act'. In relation to supervisory practice, we may perhaps think that in learning 'how to' supervise, we are not complicit in agendas of elites and assumptions about what counts as knowledge but 'As human beings, we can discover how we are conditioned by the dominant ideology. We can gain distance on our moment of existence ... we can learn how to become free' (Shor and Freire 1987, 13). More recently, similar arguments have been made by Richards (2010, 211) 'It is the commitment to the service of humanity that should define the university, not a preconceived idea of what knowledge is supposed to be'.

According to the Department for Education in the United Kingdom, coaching in its leadership programmes improves self-awareness and reflection. This fostering of self-reflection is central to the approach described here. A feature of coaching is holding back on giving advice - a difficult task for an accomplished academic. The learning principle is that students are unique and what worked for one may not work in the same way for another. Students are also capable of coming up with their own solutions. This is not to say, of course, that the supervisor would not, when it was appropriate, provide directions and directives - but for the coaching sessions or processes. The supervisor, in the role of a coach, would be expected to ask what the student would do next or what they had learnt and thought about their progress. I describe briefly the overlapping principles of three coaching models that inform the interventions designed in our supervision course. These models are Results Coaching Systems (2008), Organisation and Relationship Systems Coaching (ORSC) (Centre for Right Relationship 2005), and Coach Training International (CTI), Co-active Coach Training (Kimsey-House et al. 2011). 
Results coaching theory emerged from leadership theory, systems theory, neuro-linguistic programming and adult learning, (Rock and Page 2009). In this coaching process there is greater focus on goals and steps to achieve those goals than in the other models I draw on, although the principles of awareness, reflection and insight are common to all three models. Coach Training International uses a more flexible, creative and fluid strategy for coaching, and ORSC is primarily concerned with relationship and team coaching. Aspects of relationship and team coaching are particularly pertinent to the supervisor-student relationship. Thus these sessions may benefit the student as well as cohorts of students, and the supervisor, who has his or her own goals of ensuring the student completes successfully, and his/her own learning path in supervision. A more fluid model may at times suit 'a more chaotic view of pedagogy' as recommended by Grant $(2003,15)$. The usefulness of drawing on different models has been to see the commonalities and the practical ways in which coaching processes align with transformative learning. Coaching seeks to assist students in getting in touch with their intrinsic motivation and values; to identify how they might block their own progress; to find creative ways to gain perspective or change perspective; and to craft goals and work towards them. Coaching is aligned with a humanising pedagogy (Armstrong 2007), in that there is a strong emphasis on equity, transformative learning and actualisation (see Rhodes and Fletcher 2012).

Important principles in all three coaching models used here include empowering and challenging the student while respecting boundaries. The focus is on realising potential, and is aimed at high performing individuals (Feldman and Lankau 2005). The principles I am describing accord well with the three domains in supervision, described by Ahern and Manathunga (2004), where a student may be blocked: the cognitive, the social and the emotional. They go on to outline strategies to help students re-frame their thinking about these blocks. The contribution I wish to make to this debate is largely a practical one based on the premises of transformational and liberatory learning that provides strongly for equity and diversity.

\section{Principles of coaching}

Coaching is essentially a conversation but includes action and reflections. The alignment with learning, teaching and research is, to me, striking. 'We may consider research and teaching as conversations' (Barnett 2005, 6). This sentence also sums up the essence of the term 'enabling engagement': in order to be an engaged member of a community, one needs to be 'included in what matters' (Wenger 2004, 74). Postgraduate students need to be inducted into a community of scholars and led through the thesis requirements; but they also need to engage in new and 
creative ways of seeing the world and transforming themselves. They also need to decide 'what matters' and to be given opportunities to ponder this.

The characteristics of the supervisory interaction from a coaching perspective include processes which allow for such reflection: listening, working holistically, being learner-centred, acknowledging, not giving advice, asking forward-looking questions, exploring options, motivating, holding the student accountable. This list of principles underpins the tools I present. There is a conscious use of structure as well as creativity to deepen learning while moving the student forward.

\section{Specific coaching tools}

In the South African context, where the individual supervision structure is most prevalent (Backhouse 2010), we need to find ways to deepen the conversations that we have with students. The three processes or tools below are designed to facilitate meaningful conversations between students and supervisor:

1. Designed alliance (DA): This is an understanding of how the supervisor-student relationship will best work for this particular partnership. This goes beyond the official (but negotiated) Memorandum of Understanding (MOU) to a discussion of what type of pedagogy and communication both parties will be happy with and what each of their expectations are. This strategy is both action- and being-oriented and promotes powersharing. It is interesting to note that in Aspland, Edwards, O’Leary and Ryan's (1999, 144) proposed evaluations of the supervisory process, a number of items are targeted at interpersonal communication, for example: 'My supervisor consults me on my preferred way of working'. The designed alliance process helps to make such consultations explicit. In workshops, supervisors are asked to role-play this conversation with a 'student'. Typical questions could include: 'How would you like me to supervise you?' 'What do you need from me?' 'Let me tell you upfront the things that are non-negotiable for me ...' 'If things get difficult, how would you like us to handle it?' And of course, the student is encouraged/expected to also be frank: e.g. 'What I am most concerned about is ...'. This agreement on how they would work together would be re-visited periodically to check on how it was working and whether anything needed to change.

2. Discovery Wheel for PhD students: a self-assessment tool to provide a 'snapshot' of areas of development, concern or achievement. I have adapted the discovery wheel (a common coaching tool) for PhD students and supervisors. (See Figure 1.) 


\section{Directions}

The eight sections of the Wheel represent different aspects of your studies. Seeing the centre of the wheel as 0 and the outer edges as 10, rank your level of satisfaction with each area by drawing a curved line to create a new outer edge. 1 would mean you are very dissatisfied while 10 would be 'great!'

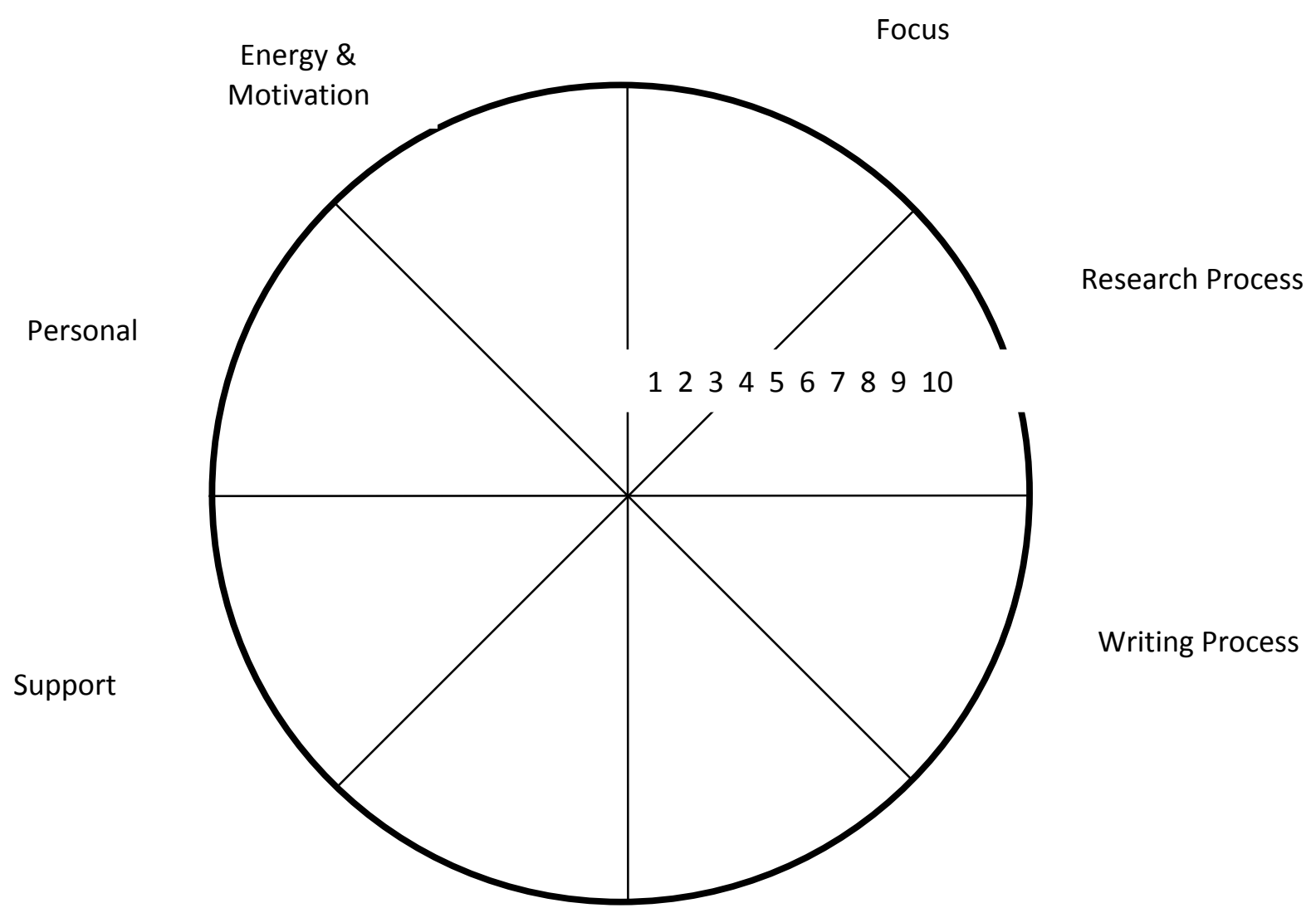

Workload in Department \&

Time Management

Supervision

Figure 1: The Discovery Wheel (Doctoral Studies)

NB: The level of satisfaction is entirely personal. You may, for example, be working 15 hours a day, but you may be perfectly satisfied with this - use your own criteria and interpretation of the categories to rate your levels.

This is a self-assessment satisfaction gauge of various aspects that may be relevant to the $\mathrm{PhD}$ journey. It may, of course, be adapted further and usually one aspect/category is left blank for the student to choose what may be relevant. The student rates their satisfaction or confidence in categories such as motivation, focus, research process, support, supervision, workload, time management, finance, personal, family, resources, and writing. The scale ranges from 1 to10 and the student marks off the sections ( 1 being the least satisfactory and 10 the most). This is a 
self-reflection exercise and a possible starting-point for a coaching conversation between supervisor and student. With the student's permission, and led by the student's needs, the supervisor could ask: 'What surprises you about this?' 'What do you notice?' 'Would you like to choose one of these to talk about?' 'What made you give resources a 5?' 'Where would you like this to be?' 'What would an 8 look like to you?' 'How could we move this to an 8?' The supervisor would then explore practical steps to help the student make progress towards his/her goals. To follow on from the example discussed:

Student: $\quad$ An 8 for me in 'resources' would mean I have a grant for buy-out of teaching so I have more time to work on my studies.

Supervisor: What would this buy-out give you? (As a supervisor I was thinking of some practical issues - such as 'time to write'. But the student, after reflecting, came up with a different insight.)

Student: I would feel that the research office or NRF had faith in me. I would be motivated by the vote of confidence.

Supervisor: What grants are available?

Student: I don't know.

Supervisor: So I would like you to email me a list of grants you are eligible for. You could speak to the Research Office. When could you do this by?

As with the designed alliance, the wheel could be reviewed after a few months to see how things had changed.

\section{Values as an academic}

1. Underline five words that most describe the values you hold as an academic/ researcher:

2. Organised

Structured

3. Challenging

Expert

4. Caring

Professional

5. Holistic

Friendly

6. Profound

Humorous

7. Innovation / invention

Persuasive

8. Creative

Championing equity

9. Authoritative

Methodical

10. Leading

Memorable

11. Versatile

Nurturing potential

12. Scholarly

Best in my field

13. Collaborative

Famous

14. Efficient

Flamboyant

15. Meticulous

Powerful

16. Shifting boundaries

Secluded

17. Objective

Making a difference

18. Inspirational

Authentic

19. Promoting freedom

Adventurous 
Figure 2: Values worksheet

Values exploration provides a way of understanding one's working style and motivation better. Discovering and sharing one's values helps with motivation and mutual understanding between supervisor and student. Students are asked to select four values from a simple 'values sheet' (see Figure 2). Deliberately reflecting on values could help students to be more aware of their way of working and that people typically prioritise different values. The supervisor may be creative, inventive, and humanistic while the student may be task-focused, practical, and objective. Again, a conversation would follow on how these values can be honoured in the relationship and in the research process.

In the workshops with supervisors, we trial this activity. Supervisors are usually surprised and interested in the different values chosen by members of their group of colleagues. Supervisors could ask students to consider how their values align with their research project. For example: if a value is 'creativity' the supervisor may ask: 'What does it mean to be creative in this project?', 'What does freedom look like for you in the supervisory relationship?' or 'My value is efficiency. What can you commit to so that I feel we are making progress efficiently?'

All three of these coaching strategies are designed to enable conversations and to shift some of the power more equitably in the student's direction. This process could lead to transformative learning where a student reflects critically on experience to create not only new meaning but new perspectives (Mezirow 2003). These new perspectives may be provoked by a more holistic learning process (Dirkx 2001) as described here.

The behaviours the supervisor desired from the student could be enhanced through the coaching principle of challenging the student, and conflicting expectations could be resolved in the designed alliance and values tools that I have described. Another example: if the supervisor seems to value initiative, independence and intellectual rigour (as suggested in some of the supervisors' comments provided above), it may help the student to be aware of this. We could postulate a cause of dissonance if the student's values are (for example): respect authority and family commitments. Of course there may be any number of actual concerns, expectations and values. These tools may provide a structured way to address these. In the absence of such a structure, it may be culturally and conventionally difficult to broach such topics or voice such sentiments. I have proposed approaches and tools for doing this.

\section{CONCLUSIONS}


I have described relevant coaching principles and three coaching tools that may be useful for inclusion in supervisor development workshops or courses. The rationale for a coaching approach (as an addition to conventional supervisory practices) is based on its principles of power-sharing, deep dialogue, holistic learning and the focus is on developing contextual intelligence. I argue that some of the difficulties experienced by supervisors and students could be addressed through the use of coaching principles and processes. The examples given illustrate how coaching processes are based on deepening one's self-awareness, improving cultural intelligence, and communicating (Middleton 2015). This is accompanied by setting goals and being held accountable. Supervisors could draw on coaching to complement the complex requirements of postgraduate pedagogy, to address some of the 'soft factors' and to help students meet their goals. Furthermore, students need to gain more than 'getting through' - they need to be able to work autonomously and function as critical, innovative and resilient leaders in a multicultural society.

While this article has described coaching tools that may be used with students, supervisors themselves need to engage with these first. Thus, an additional rationale for including these coaching processes in a supervisor's workshop is that the supervisors themselves may develop more insight into their approach and assumptions about how academia 'works'. They may develop more trust in sharing with the workshop group so that a community of practice is fostered across contexts, power divides and levels of experience. These tools also help bridge the divide between practical progress and holistic development that may otherwise be difficult to manage. Establishing a safe space for supervisors to share experiences has been one of the outcomes of these supervisory workshops, as has providing an alternative focus from the 'information providing' that is expected in such courses. The coaching aspects of supervisor workshops open up spaces for closer collegiality, greater awareness of different contexts and the modelling of empowering conversations. Future research needs to follow up the extent of workshop participants' use of these coaching tools and the possible consequences on student progression and the supervisor-student relationship.

\section{ACKNOWLEDGEMENTS}

I acknowledge the contribution of generous colleagues in the design and facilitation of the postgraduate supervision workshops that I have drawn on in this article: Professors Ahmed Wadee and Jane Castle. They are both qualified coaches and have contributed significantly to our understanding of the role of coaching in postgraduate supervision support. 


\section{NOTE}

1 Quoted with permission of the student

\section{REFERENCES}

Ahern, K. and C. Manathunga. 2004. Clutch-Starting stalled research students. Innovations in Higher Education 28(4): 237-254.

Armstrong, H. 2007. Hestia and coaching: Speaking to the 'hearth' of the matter. International Journal of Evidence Based Coaching and Mentoring. Special Issue, Summer, 2007: 30-39.

Aspland, T., H. Edwards, J. O’Leary and Y. Ryan. 1999. Tracking new directions in the evaluation of postgraduate supervision. Innovative Higher Education 24(2).

Backhouse, J. 2010. Patterns of practice in South African doctoral education: An empirical study. Acta Academica. Postgraduate supervision: Research and practice: Supplementum 1: 1-22.

Barnett, R. 2005. Reshaping the university: New relationships between research, scholarship and teaching. The Society for Research into Higher Education. Berkshire, England: Open University Press.

Bitzer, E. M. and R. Albertyn. 2011. Alternative approaches to postgraduate supervision: A planning tool to facilitate supervisory processes. South African Journal for Higher Education 25(5): 874888.

Blackmore, P., J. Chalmers, L. Huxley and B. Thackwray. 2010. Tribalism and territoriality in the staff and educational development world. Journal of Further and Higher Education 34(1): 105117.

Castle, P. J. 2013. 'I had no time to bleed': Heroic journeys of PhD students in a South African School of Education. Journal of Education 57: 103-125.

Center for Right Relationship. 2005. Organisational and Relational Systems Coaching Manual. http://www.centerforrightrelationship.com/organization-relationship-systems-coaching.html. CA.

Clegg, S. 2014. Knowledge questions and doctoral education. In Pushing the boundaries in postgraduate supervision, ed. E. Bitzer, R. Albertyn, L. Frick, B. Grant and F. Kelly, 11-24. Stellenbosch: SUN MeDIA.

Dietz, A. J., J. Jansen and A. A. Wadee. 2006. Effective PhD supervision and mentorship: A workbook based on experiences from South Africa and the Netherlands. Amsterdam: UNISA Press.

Dirkx, J. M. 2001. The power of feelings: Emotion, imagination, and the construction of meaning in adult learning. New Directions for Adult and Continuing Education 89: 63-72.

Else, H. 2014. The PhD experience: This far, and no further. Times Higher Education 14 August. http://www.timeshighereducation.co.uk/features/the-phd-experience-this-far-and-nofurther/2015113.fullarticle (accessed 16 November 2015).

Emilsson, U. M. and E. Johnsson. 2007. Supervision of supervisors: On developing supervision in postgraduate education. Higher Education Research and Development 26(2): 163-179.

Fataar, A. 2013. A pedagogy of supervision: 'knowledgeability' through relational engagement. Journal of Education 58: 111-133.

Feldman, D. C. and M. J. Lankau. 2005. Executive coaching: A review and agenda for future research. Journal of Management 3(6): 829-848.

Frame, I. A. and L. Allen. 2002. A flexible approach to $\mathrm{PhD}$ research training. Quality Assurance in Education 12(2): 98-103.

Freire, P. 1970. Pedagogy of the oppressed. New York: Continuum.

Geber, H. and M. Keane. 2013. Extending the worldview of coaching research and practice in Southern Africa: the concept of Ubuntu. International Journal of Evidence Based Coaching and Mentoring 11(2). http://www.business.brookes.ac.uk/research/areas/coachingandmentoring 
Geber, H. M. and C. J. Visser. 2012. Coaching and institutional support for law school academics during postgraduate studies and for increased publications. The International Journal of Learning 18(6): 173-186.

Geber, H. M. 2010. Coaching for accelerated research productivity in Higher Education. International Journal of Evidence Based Coaching and Mentoring 8(2): 64-78.

Geber, H. M. 2009. Research success and structured support: Developing career academics in higher education. South African Journal of Higher Education 3(4): 673-688.

Grant, B. 2001. Dirty work: ‘A code for supervision’ read against the grain. In Postgraduate research supervision: Transforming relations. ed. A. Bartlett and G. Mercer, 13-24. New York: Peter Lang Publishing.

Grant, B. 2003. Mapping the pleasures and risks of supervision. Discourse: Studies in the Cultural Politics of Education 24(2): 175-90.

Grant, A. M., J. Passmore, M. Cavanagh and H. Parker. 2010. The state of play in coaching. International Review of Industrial and Organizational Psychology 25: 125-168.

Hadingham, J. A. 2010. The experience of becoming a PhD. Unpublished PhD thesis. Johannesburg: University of the Witwatersrand.

HEFC see Higher Education Funding Council.

Higher Education Funding Council. 2012. Researchers of tomorrow: The research behaviour of Generation Y doctoral students, 1-85. London: British Council Library and Joint Information Systems Committee.

Kamler, B. and P. Thomson. 2006. Helping doctoral students write: Pedagogies for supervision. London: Routledge

Kimsey-House, L., K. Kimsey-House, H. Sandahl and P. Whitworth. 2011. Co-active coaching. London and Boston: Brealey Pubishing.

Lee, A. M. 2006. Models of facilitation. Educational Developments 7(3). Staff and Educational Developers Association. London: SEDA.

Lee, A. M. 2007. Developing effective supervisors: Concepts of research supervision. South African Journal of Higher Education 21(4): 680-693.

Mezirow, J. 2003. Transformative learning as discourse. Journal of Transformative Education 1(1): 58-63.

Middleton, J. 2015. Cultural intelligence: CQ: The competitive edge for leaders crossing borders. London: Bloomsbury.

Pearson, M. and M. Brew. 2002. Research training and supervision development. Studies in Higher Education 27(2): 135-150.

Person, M. and C. Kayrooz. 2007. Enabling critical reflection on research supervisory practice. International Journal for Academic Development 9(1): 99-116.

Richards, H. 2010. 'Human development and the transformation of the academy.' An address presented to the University of South Africa, South African Research Chairs Initiative: SARCHI. 20 November 2010.

Rock, D. and L. J. Page. 2009. Coaching with the brain in mind: Foundations for practice. New Jersey: Wiley and Sons Inc.

Results Coaching Systems. 2008. Workplace coach training manual. Sydney, Australia: Coaching Systems International Pty Ltd.

Rhodes, C. 2013. Coaching and mentoring for self-efficacious leadership in schools. International Journal of Mentoring and Coaching in Education 2(1): 47-63.

Rhodes, C. and S. Fletcher. 2012. Coaching and mentoring for self-efficacious leadership in schools. International Journal of Mentoring and Coaching in Education 2(1): 47-63.

Shor, I. and P. Freire. 1987. A pedagogy for liberation: Dialogues on transforming education. Granby, 
MA: Bergin and Garvey.

Sternberg, R. J. 1997. Thinking styles. Cambridge: Cambridge University Press.

Theeboom, T., B. Beersma and A. E. M. van Vianen. 2014. Does coaching work? A meta-analysis on the effects of coaching on individual level outcomes in an organizational context. The Journal of Positive Psychology 9(1): 1-18.

Wadee, A. A., M. Keane, T. Dietz and D. Hay. 2010. Effective PhD supervision mentoring and coaching. $2^{\text {nd }}$ Edition. South Africa-Netherlands research Programme on Alternatives in Development SANPAD. Amsterdam: Rosenberg Publishers.

Wisker, G. and G. Robinson. 2012. Picking up the pieces: Supervisors and doctoral 'orphans'. International Journal for Researcher Development 3(2): 139-153.

Wenger, E. 2004. Engagement, identity and innovation: Etienne Wenger on communities of practice. An interview by Seth Kahan. Journal of Association Leadership, January issue. 